\title{
Combination of Pulmonary Rehabilitation and Neuromuscular Electrical Stimulation in COPD Patients: A Randomized Clinical Trial of Efficacy
}

\section{Ercole Zanotti*, Catiuscia Bizzarri, Roberta Grasso and Claudio Fracchia}

Department of Pulmonary Rehabilitation, Fondazione S. Maugeri IRCCS, Scientific Institute of Montescano, 27040 Montescano (PV), Italy

\begin{abstract}
Aims: Effectiveness of combination of pulmonary rehabilitation $(\mathrm{PR})$ and neuromuscular electrical stimulation (NMPR) in severe chronic obstructive pulmonary disease (COPD) is well established. We verified the effects of NMPR compared with pulmonary rehabilitation and sham stimulation (SSPR) in patients with moderately impaired COPD.
\end{abstract}

Methods: Quadriceps strength (sit-to-stand test: STST) and exercise capacity (6 minute walking test: 6MWT) were considered primary outcomes. Lung function, dyspnoea (modified Medical Research Council: mMRC) and quality of life (St. George's Respiratory Questionnaire: SGRQ) secondary outcomes.

Results: 83 stable patients in stage II, moderate COPD (23 female; mean age, $61.7 \pm 9.1$ years; FEV $59.8 \pm 7.3 \%$ of predicted) were enrolled. Quadriceps strength was enhanced by SSPR (STST $+7 \pm 1.7$ repetitions; $p \leq 0.001)$; NMPR further increased strength $(+10 \pm 1.6$ repetitions; $p \leq 0.001)$ with a significant difference $(p \leq 0.05)$ between the treatments. SSPR significantly increased exercise capacity $(6 M W D+85.3 \pm 11.5 \mathrm{~m} ; \mathrm{p}=0.01)$; NMPR further increased the distance walked $(6 M W D+146.4 \pm 32.7 \mathrm{~m} ; \mathrm{p}=0.01)$ with a significant difference $(p \leq 0.05)$ between the treatments. None of the two treatments influenced lung function. Quality of life score (SGRQ $-8.3 \pm 2.1 ; p=0.01)$ and dyspnoea score (mMRC$0.7 \pm 0.18 ; p=0.01$ ) decreased after SSPR suggesting a positive effect. NMPR did not further improve the score.

Conclusions: This study confirms that PR is able to ameliorate quadriceps strength, exercise capacity, quality of life and dyspnoea in moderately impaired COPD patients. NMPR may further improve quadriceps strength and exercise capacity with respect to PR alone.

\section{Introduction}

Dyspnoea, peripheral muscle wasting and decreased exercise capacity are characteristics of chronic obstructive pulmonary disease (COPD) [1]. Pulmonary rehabilitation (PR) may partly reverse peripheral muscle dysfunction [2] so increasing exercises capacity.

Neuromuscular electrical stimulation (NMES) has been extensively used as a technique to improve muscle function in different areas of rehabilitation; however it seems to be more appropriate in critical care situation, while its use in more able patients is of uncertain benefit [3]. In other words, NMES seems to be particularly effective in severely deconditioned and bed ridden patients [4]. For example, NMES is able to improve peripheral muscle strength both in bed-bound patients with severe COPD still receiving mechanical ventilation [5] and in severely deconditioned and malnourished COPD [6], while it was ineffective in enhancing muscle strength and walking capacity in a group of moderately impaired COPD patients [7]. We therefore carried out a randomised trial to compare the efficacy of combination of NMES and $\mathrm{PR}(\mathrm{NM}+\mathrm{PR})$ with combination of sham stimulation and PR (SS+PR) in a large population of moderately impaired COPD patients. Primary outcomes were evaluation of effects of NMES on quadriceps strength and on exercise capacity. Secondary outcomes were evaluation of effects of NMES on symptoms (dyspnoea) and quality of life.

\section{Methods and Materials}

\section{Patients}

The study population included COPD patients consecutively admitted to our Pulmonary Rehabilitation Unit from January 2007 to March 2008. During this period 167 COPD patients were admitted to undergo an inpatient PR program. We chose to enrol only patients at their first recovery, who had never undergone PR, so as to study a "naive" population and to avoid a possible learning effect. 65 out of 167 did not meet the inclusion criteria. 19 out of the remaining 102 patients refused to participate in the study. Our definitive sample was therefore of 83 subjects who met the inclusion criteria, consented to participate and completed 25 days of training. A diagram showing the flow of participants through each stage of our randomized trial is shown in Figure 1.

Our entry criteria were diagnosis of COPD made according to the World Health Organization's Global Initiative for Chronic Obstructive Lung Disease (GOLD) definition [1]. Subjects were considered eligible for the study if they were clinically stable (i.e. had no evidence of acute exacerbation and had experienced no change in medication use during the previous 4 weeks). Exclusion criteria were: previous or current diagnosis of chronic respiratory failure; a history of diseases other than COPD, in particular neurological disease; and the need for treatment with systemic steroids during the rehabilitation period. We did not consider among exclusion criteria the presence of pacemaker, implantable cardioverter defibrillator or metal implants in the leg: however, none of the enrolled patients had these equipments.

All patients received regular treatment with inhaled bronchodilators

*Corresponding author: Ercole Zanotti, Department of Pulmonary Rehabilitation, Fondazione S. Maugeri IRCCS, Scientific Institute of Montescano, 27040 Montescano (PV) Italy, Tel: 393-8524-7324; Fax: 393-8524-7321; E-mail: john. ercole.zanotti@fsm.it

Received November 10, 2011; Accepted January 15, 2012; Published January 15,2012

Citation: Zanotti E, Bizzarri C, Grasso R, Fracchia C (2012) Combination of Pulmonary Rehabilitation and Neuromuscular Electrical Stimulation in COPD Patients: A Randomized Clinical Trial of Efficacy. J Pulmonar Respirat Med 2:112. doi:10.4172/2161-105X.1000112

Copyright: $\odot 2012$ Zanotti E, et al. This is an open-access article distributed under the terms of the Creative Commons Attribution License, which permits unrestricted use, distribution, and reproduction in any medium, provided the original author and source are credited. 


\section{Enrollment}

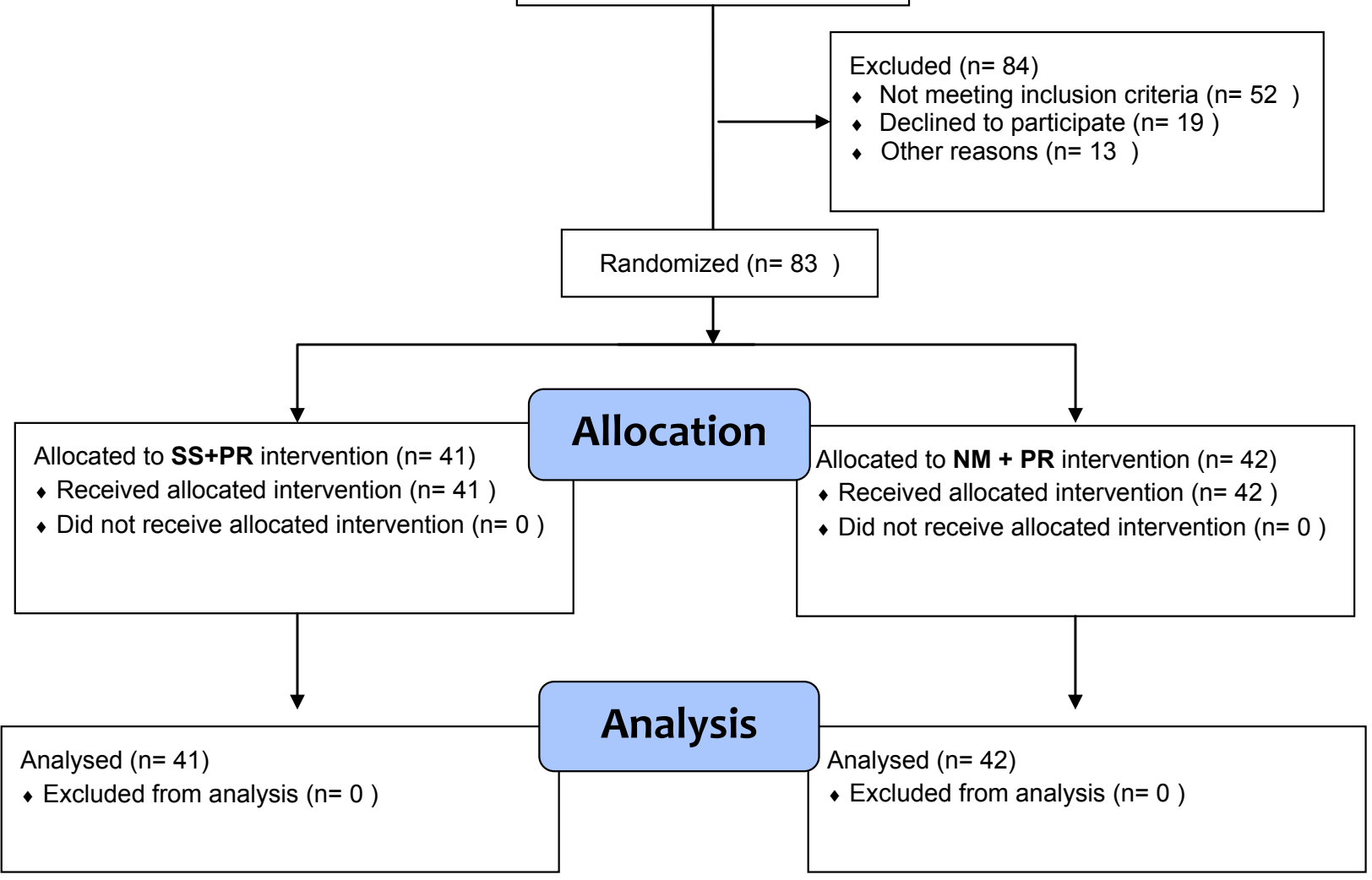

Figure 1: Diagram showing the flow of participants through each stage of the randomized trial.

and inhaled steroids according to current guidelines for their disease stage.

Patients were allocated to the intervention according to a stratified randomization that was performed through a separate randomization procedure (by means of a computer generated randomization list) considering exercise capacity. They were divided into 2 groups: SS+PR and NM+PR; SS+PR (41 patients; 12 female) underwent PR and sham stimulation, while $\mathrm{NM}+\mathrm{PR}$ (42 patients; 11 female) received quadriceps neuromuscular electrical stimulation and PR. Those who collected and analyzed clinical data were unaware of the assigned intervention. Since the patients were not in contact with each other, they remained blinded to the randomization.

The Maugeri Institutional Review Board approved the study. Each patient signed an informed consent form.

\section{Measures}

All measurements were made at the beginning and at the end of the study. The outcome assessors were blinded to the assigned intervention.

Lung function was recorded using a spirometer (Master scope body; Jaeger; Wurzburg, Germany) and a calibrated pneumotachograph. Dynamic (FVC, FEV1) and static (RV) volumes were recorded before and after $200 \mathrm{mcg}$ of inhaled salbutamol. Only post bronchodilator FEV1 was selected for the analysis.

$B M I$ was expressed as the ratio between the weight and square of height $\left(\mathrm{Kg} / \mathrm{m}^{2}\right)$.
Quadriceps strength was assessed by means of Sit to Stand Test (STST) [8]. It was performed with a standard height $(46 \mathrm{~cm})$ chair without arm rests. The subjects held their arms stationary by putting their hands on their hips. The test was first demonstrated by a respiratory therapist and then performed by the subject, who was asked to complete the sitting and standing positions without using the arms for support while rising and sitting. Once instructed, subjects stand upright and without delay sit down again, repeating the procedure as many times as possible in a $1 \mathrm{~min}$ period. The number of completed repetitions was recorded. The subjects were permitted to use rest periods to complete $1 \mathrm{~min}$.

The 6 minute-walk test (6MWT) was performed following the American Thoracic Society guidelines [9]. It was performed on the first two consecutive days to minimize intraday variability. At the beginning and at the end of exercise patients were asked to grade their level of breathing and fatigue according to the modified Borg scale [10].

The modified Medical Research Council (MMRC) scale [11] was used for rating dyspnoea. Scores range from 0 (no impairment) to 4 (maximum impairment).

Health related quality of Life (HRQL) was by the St. George's Respiratory Questionnaire (SGRQ) [12]. Scores range from 0 (no impairment) to 100 (maximum impairment).

\section{Pulmonary rehabilitation}

Patients underwent a comprehensive PR program consisting of 
exercise training, educational support, psychological counselling and nutritional intervention, if needed.

Exercise training consisted of a daily walk on treadmill for 5 days/ week for 5 weeks. Speed was $80 \%$ of the maximum speed reached on admission day. Maximum speed was defined as the speed needed to give a Borg score of 4 to 6 for dyspnoea or fatigue [10]. Length of exercise was 30 minutes. This training was similar for the whole population and was performed in the morning. Training of the muscles of ambulation has 1A grade of recommendation [13]. All participants fulfilled the treadmill training.

\section{Neuromuscular electrical stimulation}

NMES was applied by means of a commercially available four channel electrostimulator (PTS-50; TecnoBody; Lallio, Bergamo; Italy) which generated a symmetrical biphasic pulsed current. NMES was performed while patients were seated with the knee positioned at a $90^{\circ}$ fixed angle; the patients were asked not to contract quadriceps during NMES. A respiratory therapist positioned the surface electrodes on the quadriceps femoris bilaterally and set up both the program (in this case muscle training) and the initial intensity able to begin muscle contraction (about $20 \mathrm{~mA}$ at the beginning of the training session). According to the chosen program, the electrical stimulator automatically chose stimulation frequency and pulse duration. The intensity was increased weekly by approximately $5 \mathrm{~mA}$ according to the patient's tolerance. Each session lasted 30 minutes and was performed 5 days/week for 5 weeks. Sham stimulation was performed with the same modality and time, setting up intensity at $10 \mathrm{~mA}$ and frequency at $5 \mathrm{~Hz}$.

The training was performed in the afternoon. NMES training and parameters are shown in Table 1.

\section{Statistical analysis}

Analysis was performed using SAS/STAT statistical package, release 9.2 (SAS Insitute Inc, Cary, NC, USA). Sample size estimation was based on exercise capacity expressed by 6 minute walking test (6MWT). We expected that combination of NMES and PR improved 6MWT of at least $35 \mathrm{~m}$. in comparison to PR alone. We wanted to detect the treatment change with a two-tailed type I error of 0.05 and a power of $80 \%$. Accordingly, the estimated sample size was 60 (two groups of 30 patients each). To compensate for nonevaluable patients, we planned to enroll at least 40 patients for each group. The baseline characteristics were compared using the unpaired Student's $t$ test for anthropometric measurements and for physiological parameters. The effects of training were compared using paired t test for within group comparisons. Moreover, the efficacy of treatments were analysed for between group differences using analysis of variance. All data were expressed as the mean $\pm \mathrm{SD}$. The level of significance for all tests was set at $\mathrm{p}<0.05$.

\section{Results}

The sample for the analysis consisted of 83 patients, of whom 23 (27.7\%) were female. Patients were in the 60-year age group and, on average, with a normal body mass index. According to the GOLD definition [1], most of the patients were in stage II (moderate COPD), showing airflow limitation and shortness of breath during exertion.

Between group comparison of mean baseline characteristics are shown in Table 2.

There were no adverse effects or side-effects. Both PR and NMES were well tolerated.

\section{After training effects in $\mathrm{SS}+\mathrm{PR}$ vs $\mathrm{NM}+\mathrm{PR}$ groups}

Results are summarized in Table 3.

Primary outcomes: Quadriceps strength was enhanced by PR alone, with further increase on adding NM to PR. Together with the increase in muscle strength $6 \mathrm{MWT}$ also showed a significant improvement. As expected, PR alone was able to significantly increase 6MWD; adding NM to PR led to a further and significant gain in the distance walked.

Secondary outcomes: None of the two treatments influenced lung function. Both quality of life and dyspnoea scores improved after $\mathrm{PR}$, suggesting a positive effect. Combination of NM with PR did not further improve the scores.

\section{Discussion}

We believe this to be the first large powered randomized clinical trial investigating the likely effects of NMES in patients affected by stage II, moderate COPD. The main result of this study was that combination of NMES and PR was able to significantly improve quadriceps strength and exercise capacity in comparison to PR alone.

\section{Primary outcome: NMES and muscle strength}

NMES has been widely used to limit the atrophy that occurs with immobilization [14]. While it is well known that it constitutes an effective way to increase strength in healthy subjects and in impaired muscles (mainly because of anterior cruciate ligament reconstruction) [15], its role in patients with COPD is still unclear. In a previous study involving bed-bound patients with COPD receiving mechanical ventilation after ICU stay, we showed that NMES caused an increase in muscle strength and reduced the number of days for transfer from bed to chair [5]. In the present study we showed an increase in muscle strength, as assessed by STST, in both groups, with a significant difference between the two groups. This is in keeping with studies that showed that NMES may result in muscle strength improvement both

\begin{tabular}{|l|l|}
\hline Training duration, wk & 5 \\
\hline No. of sessions & 25 \\
\hline Session duration, min. & 30 \\
\hline Pulse duration, ms & 0.4 \\
\hline Stimulation frequency, $\mathrm{Hz}$ & $60-80\left(^{*}\right)$ \\
\hline Intensity, $\mathrm{mA}$ & 20 up to 60 (gradually increasing by 5$)\left(^{* *}\right)$ \\
\hline Contraction time, s & 8 \\
\hline Resting time, s & 8 \\
\hline Duty cycle, \% & 50 \\
\hline
\end{tabular}

(*) $5 \mathrm{~Hz}$ ws used for sham stimulation, warm up and resting phase. (**) $10 \mathrm{~mA}$ was used for sham stimulation

Table 1: NMES training and parameters.

\begin{tabular}{|l|l|l|l|}
\hline & SS+PR & NM+PR & -Value \\
\hline Age, years & $61.5 \pm 9.7$ & $62.05 \pm 8.5$ & 0.87 \\
\hline BMI, Kg/m & $24.7 \pm 2.5$ & $24.5 \pm 3.1$ & 0.29 \\
\hline Post BD FEV1, \% predicted & $59.6 \pm 8.2$ & $60.1 \pm 6.4$ & 0.89 \\
\hline 6MWT, m & $462.7 \pm 96.9$ & $465.5 \pm 101.7$ & 0.88 \\
\hline STST, repetitions & $13.6 \pm 0.99$ & $13.5 \pm 0.83$ & 0.37 \\
\hline MMRC, score & $2.6 \pm 0.2$ & $2.4 \pm 0.4$ & 0.42 \\
\hline SGRQ, total score & $42.05 \pm 15.7$ & $41.7 \pm 14.8$ & 0.52 \\
\hline $\mathrm{PaO}_{2}, \mathrm{~mm} \mathrm{Hg}$ & $74.2 \pm 11.6$ & $75.7 \pm 9.3$ & 0.73 \\
\hline $\mathrm{PaCO}_{2}, \mathrm{~mm} \mathrm{Hg}$ & $42.4 \pm 3.2$ & $43.5 \pm 2.9$ & 0.59 \\
\hline
\end{tabular}

Table 2: Baseline characteristics (mean value \pm SD) of the two groups of patients. SS+PR: sham stimulation + pulmonary rehabilitation - NM+PR: neuromuscular electrical stimulation + pulmonary rehabilitation. BD: Bronchodilator. 
in severely disabled patients [6] and in patients with moderate to severe COPD [16,17]. Napolis et al. [18] very recently showed the effects of NMES on exercise capacity in mildly impaired patients with COPD. They performed 6-weeks, home based, hf-NMES $(50 \mathrm{~Hz})$ followed by sham stimulation of the quadriceps femoris in a randomized, crossover study on thirty patients with functional features very similar to our population (FEV1 $49.7 \pm 13.4 \%$ predicted). They measured concentric isokinetic knee-extensor strength using an isokinetc dynamometer. They were not able to show a change in muscle strength. However, exercise capacity was significantly improved in a subgroup of "responders" who had a better-preserved fat-free mass and a higher tolerance for hf-NMES. Their results suggested that early training with hf-NMES before muscle wasting begins might be useful for enhancing exercise tolerance in COPD patients who are not yet severely disabled. Two recent systematic reviews $[3,19]$ summarized all the above reported data.

\section{Primary outcome: NMES and exercise capacity}

As reported for muscle strength, effects of NMES on exercise capacity are unclear. Some studies $[5,16,17]$ reported an increase in exercise capacity, while other studies $[6,7]$ did not show significant increase in 6MWD. In the present study we found a significant increase in 6MWD irrespective of the treatment, however there was a significant $(p=0.005)$ difference between the two groups. Exercise capacity is crucial in patients with COPD: indeed, they are inactive in daily life because of the dyspnoea and this inactivity is an additional factor that leads to muscle weakness [20]. Our results are over the gain threshold for clinical significance, i.e. the so called minimal important difference (MID) that is defined as "the smallest difference in score in the outcome of interest that informed patients or informed proxies perceive as important and which would lead the patient or clinician to consider a change in the management". This latter is still debated $[9,21,22]$ and recently the existence of an MID for the 6MWT in patients with COPD has been questioned. A retrospective study [23] using clinical trial data found a poor correlation between change in 6MWD and patientreported change on quality of life questionnaires: the authors conclude that the 6MWT may not be an outcome of importance to patients and that no MID exists. More recently MID for 6MWT has been updated [24]: in patients with COPD there was a mean improvement in 6MWD of 66 meters after PR and the MID for the 6MWD was approximately 25 meters. In our study, patients who underwent PR showed a mean increase in the 6MWD of 85 meters or $23 \%$ : this percentage of walking distance improvement in patients with COPD was similar to those reported by Troosters et al. [25]. Combination of PR and NMES led to a further mean increase in the 6MWD of approximately 60 meters or $40 \%$. To the best of our knowledge this is the first study that shows a significant effect of NMES on exercise capacity in moderately compromised COPD patients.

\section{Secondary outcome: NMES and dyspnoea}

Dyspnoea is a symptom associated with exercise performance and, therefore, quality of life. One of the major goals of COPD treatment is a reduction in dyspnoea. Two studies about NMES [6,17] showed that it may reduce dyspnoea. We evaluated dyspnoea by means of the modified Medical Research Council (mMRC) dyspnoea scale, a simple to use, validated, reproducible, self-assessed tool of breathlessness [11]. International guidelines suggest that COPD patients that may benefit from PR must have from 3 to 5 grades on the mMRC dyspnoea scale, while currently patients with mMRC grade 2 breathlessness (i.e. patients with mild disability) are not included in the guidelines [26]. However, it has been shown that PR may improve exercise performance in COPD patients with mMRC grades 1 and 2 breathlessness as much as in patients with mMRC grades 3 and 4 [27]. More recently, it has been shown in a large cohort of patients with COPD that benefits of PR apply equally to people with mild (mMRC2) and severe (mMRC5) disability [28]. In the present study our patients had a mild disability and showed an mMRC mean entry grade of $2.5 \pm 0.3$. PR led to a mean improvement in rating dyspnoea score of $0.7(\mathrm{p}<0.005)$ in accordance with the data of Evans and colleagues [28]. We did not show a further improvement due to combination of NMES and PR. Our results contribute to show that patients with mild disability (mMRC2) may also benefit from PR.

\section{Secondary outcome: NMES and quality of life}

Among studies about NMES, only two analyzed quality of life. In particular, Vivodtzev at al. [6] measured quality of life using the 28-item Maugeri Foundation Respiratory Failure questionnaire (MRF-28). It is a self-administered disease-specific questionnaire particularly close to the lifestyle of COPD patients. The following three domains were investigated: daily activity (i.e. sensation of dyspnea in daily tasks); cognitive function (i.e. loss of memory and concentration capacity); and invalidity. They showed a significant decrease in the score of the "dyspnea in daily tasks" domain of the MRF-28 in the group treated with NMES compared to that treated only with PR. Neder et al. [17] measured quality of life by means of the Chronic Respiratory Questionnaire (CFD). In this instrument four domains are measured: "dyspnoea" (using self-selected daily activities), "fatigue", "mastery", and "emotional function". They showed that NMES was associated with beneficial changes only in dyspnoea domain. We evaluated quality of life using the St. George's Respiratory Questionnaire (SGRQ) that is a standardized self-administered airways disease-specific questionnaire divided into three subscales: symptoms (8 items), activity (16 items), and impacts (26 items). For each subscale and for the overall questionnaire, scores range from 0 (no impairment) to 100 (maximum impairment). In the present study our population showed an entry mean total score of $41.5 \pm 19.8$. It means that our patients are

\begin{tabular}{|c|c|c|c|c|c|c|c|}
\hline Measure & SS & PR & Post - Pre Difference & NM & PR & Post - Pre Difference & Between group difference \\
\hline & pre & post & & pre & post & & \\
\hline $\begin{array}{l}\text { Post BD FEV1, } \\
\% \text { predicted }\end{array}$ & $\begin{array}{l}59.6 \pm \\
8.2\end{array}$ & $\begin{array}{l}68.7 \pm \\
4.7\end{array}$ & $\begin{array}{l}9.1 \pm \\
2.5\end{array}$ & $\begin{array}{l}60.1 \pm \\
6.4\end{array}$ & $\begin{array}{l}68.4 \pm \\
5.3\end{array}$ & $\begin{array}{l}8.3 \pm \\
1.1\end{array}$ & \\
\hline $\begin{array}{l}6 \mathrm{MWT}, \\
\text { meters }\end{array}$ & $\begin{array}{l}462.7 \pm \\
96.9\end{array}$ & $\begin{array}{l}548 \pm \\
54.2\end{array}$ & $\begin{array}{l}85.3 \pm \\
11.5^{*}\end{array}$ & $\begin{array}{l}465.5 \pm \\
101.7\end{array}$ & $\begin{array}{l}611.9 \pm \\
67.2\end{array}$ & $\begin{array}{l}146.4 \pm \\
32.7^{\star *}\end{array}$ & $<0.05$ \\
\hline $\begin{array}{l}\text { STST, } \\
\text { repetitions }\end{array}$ & $\begin{array}{l}13.6 \pm \\
0.99\end{array}$ & $\begin{array}{l}20.6 \pm \\
2.6\end{array}$ & $7 \underbrace{ \pm}$ & $\begin{array}{l}13.5 \pm \\
0.83\end{array}$ & $\begin{array}{l}23.6 \pm \\
2.4\end{array}$ & $\begin{array}{l}10.1 \pm \\
1.6^{\star \star}\end{array}$ & $<0.05$ \\
\hline $\begin{array}{l}\text { MMRC, } \\
\text { score }\end{array}$ & $\begin{array}{l}2.6 \pm \\
0.2\end{array}$ & $1.9 \pm$ & $\begin{array}{l}-0.7 \pm \\
0.18^{*}\end{array}$ & $\begin{array}{l}2.4 \pm \\
0.4\end{array}$ & $\begin{array}{l}1.7 \pm \\
0.17\end{array}$ & $\begin{array}{l}-0.7 \pm \\
0.19^{*}\end{array}$ & \\
\hline $\begin{array}{l}\text { SGRQ, } \\
\text { total score }\end{array}$ & $\begin{array}{l}42.05 \pm \\
15.7\end{array}$ & $\begin{array}{l}33.75 \pm \\
8.9\end{array}$ & $\begin{array}{l}-8.3 \pm \\
2.1^{* \star}\end{array}$ & $\begin{array}{l}41.7 \pm \\
14.8\end{array}$ & $\begin{array}{l}32.4 \pm \\
8.15\end{array}$ & $\begin{array}{l}-9.3 \pm \\
1.5^{* \star}\end{array}$ & \\
\hline
\end{tabular}

Table 3: Functional results in group of patients treated with pulmonary rehabilitation plus sham stimulation (SS+PR) and in group of patients treated with pulmonary rehabilitation and neuromuscular electrical stimulation (NM+PR). Results are expressed as mean $\pm S D$. ${ }^{*} p=0.001{ }^{* *} p \leq 0.001$. 
located on percentile 90, indicating a high impact of COPD on quality of life [29]. Both groups of patients showed a clinically significant total score improvement, over the 4 unit threshold for clinical significance [30]. NMES did not lead to a further improvement. This is in contrast with previously published data as above specified [6,17]. A possible explanation is that we studied patients with moderate COPD, with a likely less compromised quality of life. Unfortunately, comparison is impossible due to the use of different quality of life questionnaires. However, the real value of NMES on quality of life is still uncertain [4].

\section{Study limitations}

The most important limitation of this study is probably the method we adopted to measure muscle strength. Since we operate in a respiratory ward, we have a lack of experience with weight machines, portable dynamometer or more complex systems. This is the reason we used manual muscle testing (MMT) to evaluate muscle strength. We acknowledge that appropriate assessment of peripheral muscle strength is essential for identifying muscle weakness and evaluating treatment effectiveness and we tried to adopt a simple, but accurate and reliable method, to obtain the best possible result. The sit-to-stand movement is a function people frequently use as they change from a sitting position to a standing position. The ability to go from a sitting position to a standing position is an important skill; in elderly people, the inability to perform this basic skill can lead to institutionalization, impaired functioning and mobility in activities of daily living and even death [31]. It has been determined that the passage from sitting to standing position is influenced not only by lower limbs muscle strength but also by multiple physiological and psychological processes [32]. However, it is evident that quadriceps muscle strength is very important to arise from a chair [33]. Ozalevi et al. [8] have indicated STST as able to identify peripheral muscle weakness in patients with COPD and therefore an alternative to indirectly measure lower limbs strength. Moreover, they considered STST as a predictor of severity [8]. Furthermore, a significant correlation has been recently shown between the number of repetitions of STST and the total BODE index score (which is correlated with survival in COPD) suggesting that the STST can reflect a worse prognosis for individuals with COPD [34,35]. Keeping these data in mind we speculate that measuring effect of NMES on STST could indicate not only the influence of NMES on muscle strength, but also on prognosis. Moreover, these results substantiate analogous results obtained with NMES on $6 \mathrm{MWT}$ either in the present and in others studies $[5,16,17]$. Indeed, STST determines the functional state correctly like $6 \mathrm{MWT}$ in patients with moderate-to-severe COPD [8].

Another possible important limitation is the selection of patients. We acknowledge that when NMES is considered, the level of muscle impairment is possibly the most important indicator to take into account [3]. So far NMES is considered appropriate in patients who are confined to bed rest and/or severely disabled $[3,19,36]$. However, it has been already shown that early training with NMES before muscle wasting begins might be useful for enhancing exercise tolerance in COPD patients who are not yet severely disabled [18]. Moreover, it is well known that COPD is related to a broad array of physical function limitations including lower extremity functioning, exercise performance, skeletal muscle strength and self reported limitation in basic physical action [37]. The development of these functional limitations is the first step in the pathway to developing disability in COPD [38]. Respiratory rehabilitation has traditionally been provided in secondary care during the stable phase of the disease to patients with moderate to severe disease. Current concepts are however recommending that it should be delivered in a primary and community care setting for patients with milder disease [39]. In our setting we consider NMES as a part of respiratory rehabilitation. We do not consider NMES as an alternative to exercise training in patients who are able to voluntarily exercise, but as an adjunct to exercise training. Currently the selection criteria for PR are directed at patients with established disability rather than at preventing future disability. There is a well-described cycle of decline for the exertional symptoms of COPD; patients avoid their symptoms by becoming less active leading to de-conditioning which in turn worsens the symptoms. It may be possible to interrupt this cycle early in patients with mild disability [28]. NMES may help to do it.

\section{Conclusion}

This study showed that combination of NMES and PR is able to further improve exercise capacity and quadriceps strength in patients with stage II, moderate COPD compared to PR alone.

NMES could be a complementary tool that should improve efficiency of pulmonary rehabilitation training. New studies should be set up in a larger population to validate use of NMES in PR.

\section{References}

1. [Author not Listed] (2008) From the Global Strategy for the Diagnosis Management and Prevention of COPD, Global Initiative for Chronic Obstructive Lung Disease (GOLD)

2. Ambrosino N, Strambi S (2004) New strategies to improve exercise tolerance in chronic obstructive pulmonary disease. Eur Respir J 24: 313-322.

3. Roig M, Reid WD (2009) Electrical stimulation and peripheral muscle function in COPD: a systematic review. Respir Med 103: 485-495

4. Vivodtzev I, Lacasse Y, Maltais F (2008) Neuromuscular electrical stimulation of the lower limbs in patients with chronic obstructive pulmonary disease. $J$ Cardiopulm Rehabil and Prev 28: 79-91.

5. Zanotti E, Felicetti G, Maini M, Fracchia C (2003) Peripheral muscle strength training in bed-bound patients with COPD receiving mechanical ventilation: effect of electrical stimulation. Chest 124: 292-296.

6. Vivodtzev I, Pépin JL, Vottero G, Mayer V, Porsin B, et al. (2006) Improvement in quadriceps strength and dyspnea in daily tasks after 1 month of electrical stimulation in severely deconditioned and malnourished COPD. Chest 129: 1540-1548.

7. Dal Corso S, Nàpolis L, Malaguti C, Gimenes AC, Albuquerque A, et al. (2007) Skeletal muscle structure and function in response to electrical stimulation in moderately impaired COPD patients. Respiratory Medicine. 101: 1236-1243.

8. Ozalevli S, Ozden A, Itil O, Akkoclu A (2007) Comparison of Sit-to-Stand Test with 6 min walk test in patients with COPD. Respir Med 101: 286-293.

9. [Author not listed] (2002) ATS statement: Guidelines for the Six-Minute Walk Test. Am J Respir Crit Care Med 166: 111-117.

10. Borg G (1990) Psychophysical scaling with applications in physical work and the perception of exertion. Scand J Work Environ Health 16: 55-58.

11. Mahler D, Wells C (1988) Evaluation of clinical methods for rating dyspnea Chest 93: 580-586.

12. Jones PW, Quirk FH, Baveystock CM, Littlejohns P (1992) A self-complete measure of health status for chronic airflow limitation. The St. George Respiratory Questionnaire. Am Rev Respir Dis 145: 1321-1327.

13. Ries LA, Bauldoff GS, Carlin BW, Casaburi R, Emery CF, et al. (2007) Pulmonary Rehabilitation: Joint ACCP/AACVPR Evidence-Based Clinical Practice Guidelines. Chest 131: 4S-42S

14. Vanderthommen M, Duchateau J (2007) Electrical stimulation as a modality to improve performance of the neuromuscular system. Exerc Sport Sci Rev 35 180-185.

15. Bax L, Staes F, Verhagen A (2005) Does neuromuscular electrical stimulation strengthen the quadriceps femoris? A systematic review of randomised controlled trials. Sports Med 35: 191-212. 
Citation: Zanotti E, Bizzarri C, Grasso R, Fracchia C (2012) Combination of Pulmonary Rehabilitation and Neuromuscular Electrical Stimulation in COPD Patients: A Randomized Clinical Trial of Efficacy. J Pulmonar Respirat Med 2:112. doi:10.4172/2161-105X.1000112

16. Bourjeily-Habr G, Rochester CL, Palermo F, Snyder P, Mohsenin V (2002) Randomised controlled trial of transcutaneous electrical stimulation of the lower extremities in patients with chronic obstructive pulmonary disease. Thorax 57: 1045-1049.

17. Neder JA, Sword D, Ward SA, Mackay E, Cochrane LM, et al. (2002) Home based neuromuscular electrical stimulation as a new rehabilitative strategy for severely disabled patients with COPD. Thorax 57: 333-337.

18. Napolis LM, Dal Corso S, Neder AJ, Malaguti C, Oliveira Gimenes AC, et al. (2011) Neuromuscular electrical stimulation improves in chronic obstructive pulmonary disease patients with better preserved fat- free mass. Clinics 66: 401-406.

19. Sillen MJ, Speksnijder CM, Eterman RM, Janssen PP, Wagers SS, et al. (2009) Effects of Neuromuscular Electrical Stimulation of Muscles of Ambulation in Patients with Chronic Heart Failure or COPD: A Systematic Review of the English-Language Literature. Chest 136: 144-161.

20. Papaioannou AI, Loukides S, Gourgoulianis KI, Kostikas K (2009) Globa assessment of the COPD patient: time to look beyond FEV1? Respiratory Medicine 103: 650-660.

21. Wise RA, Brown CD (2005) Minimal clinically important differences in the sixminute walk test and the incremental shuttle walking test. COPD 2: 125-129.

22. Patel SA, Sciurba FC (2005) Emerging concepts in outcome assessment for COPD clinical trials. Semin Respir Crit Care Med 26: 253-262.

23. Puhan MA, Mador MJ, Held U, Goldstein R, Guyatt GH, et al. (2008) Interpretation of treatment changes in 6 minute walk distance in patients with COPD. Eur Respir J 32: 637-643.

24. Holland AE, Hill CJ, Rasekaba T, Lee A, Naughton MT, et al. (2010) Updating the minimal important difference for six-minute walk distance in patients with chronic obstructive pulmonary disease. Arch Phys Med Rehabil 91: 221-225.

25. Troosters T, Gosselink R, Decramer M (2001) Exercise training in COPD: how to distinguish responders from nonresponders. J Cardiopulm Rehabil 21: 1017.

26. Nici L, Donner C, Wouters E, Zuwallack R, Ambrosino N, et al. (2006) American Thoracic Society/European Respiratory Society statement on pulmonary rehabilitation. Am J Respir Crit Care Med 173: 1390-1413.
27. Garrod R, Marshall J, Barley E, Jones PW (2006) Predictors of success and failure in pulmonary rehabilitration. Eur Respir J 27: 788-794.

28. Evans RA, Singh SJ, Collier R, Williams JE, Morgan MD (2009) Pulmonary rehabilitation is successful for COPD irrespective of MRC dyspnoea grade. Respir Med 103: 1070-1075.

29. Ferrer M, Villasante C, Alonso J, Sobradillo V, Gabriel R, et al. (2002) Interpretation of quality of life scores from the St. George's Respiratory Questionnaire. Eur Respir J 19: 405-413.

30. Jones PW (2005) St. George's Respiratory Questionnaire: MCID. COPD 2: 75-79.

31. Jansenn WG, Bussmann HB, Stam HJ (2002) Determinants of sit-to stand movement: a review. Phys Ther 82: 866-879.

32. Lord SR, Murray SM, Chapman K, Munro B, Tiedemann A (2002) Sit-tostand performance depends on sensation, speed, balance and psychological status in addition to strength in older people. J gerontol A Biol Sci Med Sci 57 M539-M543.

33. Scarborough DM, Krebs DE, Harris BA (1999) Quadriceps muscle strength and dynamic stability in elderly persons. Gait posture 10: 10-20.

34. Rocco CC, Sampaio LM, Stirbulov R, Correa JC (2011) Neurophysiological aspects and their relationship to clinical and functional impairment in patients with COPD. Clinics (Sao Paulo) 66: 125-129.

35. Regueiro EM, Di Lorenzo VA, Basso RP, Pessoa BV, Jamami M, et al. (2009) Relationship to BODE index to functional tests in COPD. Clinics (Sao Paulo) 64: 983-988.

36. Vivodtzev I, Lacasse $Y$ (2009) Stimulating advances in chronic heart failure and COPD. Chest 136: 5-6.

37. Eisner MD, Blanc PD, Yelin EH, Sidney S, Katz PP, et al. (2008) COPD as a systemic disease: impact on physical functional limitations. Am J Med 121 789-796.

38. Verbrugge LM, Jette AM (1994) The disablement process. Soc Sci Med 38 $1-14$.

39. Ambrosino N, Casaburi R, Ford G, Goldstein R, Morgan MD, et al. (2008) Developing concepts in the pulmonary rehabilitation of COPD. Respir Med 102: S17-S26. 